\title{
Arne Bjerhammar- a personal summary of his academic deeds
}

DOI: https://doi.org/10.1515/jogs-2020-0117

Received February 3, 2021; accepted April 8, 2021

\begin{abstract}
Arne Bjerhammar is well known worldwide mainly for his research in physical geodesy but also for introducing a new matrix algebra with generalized inverses applied in geodetic adjustment. Less known are his developments in geodetic engineering and contributions to satellite and relativistic geodesy as well as studies on the relation between the Fennoscandia land uplift and the regional gravity low. Most likely part of his research has contributed to worldwide political relaxation during the cold war, which deed was honored by a certificate of achievement awarded by the Department of Research of the US army as well as the North Star Order by the King of Sweden.

Arne Bjerhammar's pioneer scientific production, in particular on a world geodetic system, towards what would become GPS, as well as relativistic geodesy, is still of great interest among the worldwide geodetic community, while the memories and spirit along his outstanding academic deeds have more or less fainted away from his home university (KTH) only a decade after he passed away.
\end{abstract}

Keywords: Arne Bjerhammar, North Star Order, Physical Geodesy, Political relaxation

"People who do not look back at their ancestors cannot look forward to posterity."

Edmund Burke (1729-1797)

\section{Introduction}

Until 1949 the only professorship in Sweden was at Royal Institute of Technology (KTH), but during the 1950ties - 1970ties new professors of geodesy were installed at $\mathrm{KTH}$, the Swedish Mapping Authority (RAK) and Uppsala University, sometimes called "the three Swedish kings of geodesy". This was a time when geodesy developed very fast, not the least due to the birth of satellite geodesy and

*Corresponding Author: L. E. Sjöberg: University West, Dept. of
Engineering Science, Trollhättan, Sweden, E-mail: larsjo@hv.se computer technology. After the $2^{\text {nd }}$ world war considerable resources were also spent on strengthening the geodetic cooperation in Europe, e.g., by starting works on the European horizontal and vertical geodetic networks (RETRIG and UELN) as well as introducing the Nordic Geodetic Commission for close cooperation within the Nordic countries. During the 1950-ties to 70-ties much of Swedish Geodesy was led by the three professors. They were all born between 1913 and 1917 in the southern half of Sweden.

C. F. Erik Tengström (1913-1996), was the oldest among the three, with one of his ancestors being Jacob Tengström, the first archbishop in Finland. He was grown up in the small town Motala, where his father was a schoolteacher. In 1932 he started his academic training at Stockholm High School by studying astronomy, physic and geology. After a few years of teaching geodesy at KTH and working as a State Geodesist at the RAK between 1949 and 1954, he defended his PhD in Geodesy at Uppsala University (UU) (Tengström 1954). Thereafter he taught geodesy at UU, and as a researcher, financially supported by the National Research Foundation from 1962 and with professor's title from 1968, he created the Hällby unit of Geodesy with an observatory in the outskirts of Uppsala. Since 1960 he participated in several (and chaired two) International Association of Geodesy (IAG) study groups and was, finally, an IAG vice president in 1979-1983. He published about 60 scientific reports and articles, and several foreigners got their PhDs in Geodesy with him at UU. On his 70-ties birthday he was honored by the Aboa Astronomic Observatory (whose personnel he was in close contact with ever since his early academic days as a pioneer astronomer at Saltsjö Baden observatory outside Stockholm) by their naming the newly discovered asteroid no. 2195 Tengström. His grave can be found at Uppsala old graveyard. (See also Sjöberg 1996)

Lars E. G. Asplund was born in 1914 at Flen, about $100 \mathrm{~km} \mathrm{SW}$ of Stockholm. He got a M.Sc. degree in Surveying Engineering in 1936, a PhD in 1945 (Asplund 1945) and was appointed Docent in 1946, all in Geodesy at KTH. He was later employed by the RAK, where he was appointed head of the geodetic department as technical director with Professor's title in 1949. Since 1952 he was also appointed 
"special teacher" (adjunct professor) in Geodesy II (Higher Geodesy) at KTH. In 1956 he was the UN advisor in geodesy at the Pakistan government. Later, after the RAK and the Swedish Survey had merged to the Swedish National Land Survey, he was appointed vice Director General, a position he kept till his retirement in 1979.

L. Asplund is "the father of the Nordic Geodetic Commission" in the sense that the commission, created in 1953, followed his proposal from 1950 (see Andersen 2001). The NKG is still, after almost 70 years, a very active player in Nordic geodesy.

Arne E. Bjerhammar (1917-2011) was the youngest in the triple. He was born in Båstad in the south of Sweden, where his father was a hotel director. After completing high school in Helsingborg in 1938 followed by military service, he started his studies at KTH, where he completed a M.Sc. in Surveying (1942), Doctor's Grade in 1948 (see Bjerhammar 1948a) and was appointed Docent (1950) and Professor of Geodesy (1952), all at KTH, where he was active till his retirement in 1983. (See also Sjöberg 2011.) In the following we will briefly summarize his academic activities.

\section{Bjerhammar as teacher and administrator}

Having Bjerhammar as teacher was always interesting, as his lectures rather often did not follow the plan, but instead presented new research results that was not always easy to understand for the poor student. However, his textbook (Bjerhammar 1962a) was useful for self-learning. In any case, it was always amusing and inspiring to listen to his lectures and speeches.

He had the Swedish Doctor's Grade, which was achieved with little or no formal supervision. About 1970 the Swedish PhD system changed to better accord with those in other European countries, where the supervisor should be active, and the formal study period was set to 4 years. This change of system was obviously not very easy for Bjerhammar, and when he retired he had supervised only 3 and 2 successful Ph.D. students in the fields of Geodesy and Seismology, respectively.

Until about 1970 most KTH departments were small with little administration headed by the chair professor as a "pope". In 1971 KTH selected Bjerhammar's department as one among the first to introduce "university democracy" with a departmental board, and naturally Bjerhammar was much against this change. Unfortunately, as he even declined to be a member of the board, the adminis- tration became extraordinary complicated with lots of internal problems that continued till his retirement. As we will see, despite these problems he was able to make outstanding pioneer research in several areas of geodesy.

\section{Bjerhammar's research}

Below we shortly describe most of Bjerhammar's research topics, but the reference list is far from complete. In total he wrote about 200 scientific papers, the majority of which were published as internal reports at KTH. He wrote two textbooks: Bjerhammar (1962a) and (1973).

\subsection{Instrument constructions and related research}

Bjerhammar's dissertation (Bjerhammar 1948a) was attached with his prototype of a tacheometer, which indicates his ability as an inventor. For most of his active time at KTH he worked on various new ideas in constructing and improving geodetic instruments, specifically electrooptical distance meters (EDMs), and an electrical engineer was employed as his assistant. One successful example of this research is the patented resolver (a refined modulation system), which considerably simplified the observations with EDMs. The resolver was commercially introduced in Geodimeter Model 6A in 1967 (AGA Geodimeter is a world famous Swedish EDM instrument). To improve and simplify the determination of the refractive index along the EDM sightline, he also constructed a device, described in Sjöberg (1976). In 1970 he took 5 students (including myself) with him and used a laser geodimeter to take observations along the $22 \mathrm{~km} \pm 2 \mathrm{~mm}$ long Niinisaalo - Phinary baseline in Finland in a two-week experiment to determine the velocity of light (Bjerhammar 1972). Based on his results he recommended the velocity $299792.4 \pm 0.1 \mathrm{~m} / \mathrm{s}$.

In 1977 he experimented with a more flexible laser geodimeter type and prisms hanging from a helicopter, trying air-trilateration over extended and/or hidden sightlines.

\subsection{Matrix algebra and adjustment theory}

Bjerhammar (1948b) started a long-time research on using matrix calculus for the adjustment of linear systems of equations, which culminated in his textbook, Bjerhammar (1973). The reference list of the textbook includes 10 of 
his related papers published in Swedish and international journals. In Bjerhammar (1955) and later Rao (1962), the generalized matrix inverse was implicitly defined by a matrix equation, followed by its general solution in Bjerhammar (1957). Thereby the tools were defined for presenting his generalized matrix algebra, successfully used in adjustment theory (e.g., Bjerhammar 1957 and 1973).

An interesting note is that the generalized inverse, defined by Bjerhammar (1955), is hardly recognized in mathematical literature even today, but the unique pseudoinverse/More-Penrose inverse is generally called the generalized inverse. See for instance Freeden and Nashed (2018, p. 207).

\subsection{Physical geodesy}

In 1962 Bjerhammar studied Molodensky's approach to determine the shape of the Earth by the geoid replaced by the quasigeoid. As an alternative approach Bjerhammar (1962b) and (1963) first used analytical continuation of surface gravity anomalies to an internal sphere ("the Bjerhammar sphere"), where the traditional spherical integral formulas could easily be applied to determine components of the external gravity field, such as the quasigeoid, the external gravity anomaly and its derivatives and deflections of the vertical. This approach has ever since been used and further developed at the KTH School of Geodesy for quasi- and geoid determination. For instance, the national Swedish and Estonian geoid models and the latest Nordic Geodetic Commission Geoid Model, NKG2015, (Ågren et al. 2016) use this approach.

\subsection{Satellite geodesy (including WGS)}

In 1969 Bjerhammar published two papers on taking advantage of artificial satellites in unique approaches for determining the Earth's gravity field (Bjerhammar 1969a and 1969b). Both studies were first undertaken while Bjerhammar worked in U.S.A. in 1967.

In the first paper he presents a method to determine the spherical harmonic coefficients of the Earth's gravity field using the energy integral for satellites. Assuming that the absolute velocity of a satellite can be observed, the harmonic coefficients can easily be determined from a linear set of observation equations. Today, this method can be more efficiently applied by data from the twin-satellite mission GRACE.

Bjerhammar (1969b) presents a method to determine “a coalescent world geodetic system” consisting of sta- tion coordinates, deflections of the vertical and a geoid model based on a combination of gravimetric and geometric satellite data. This original idea was later realized in the World Geodetic Systems WGS 1972 and WGS 1984, closely related with the Transit-Doppler and GPS systems, respectively.

\subsection{Relativistic geodesy}

Based on a discussion with Prof. O. Rydbeck (the founder of Onsala Space Observatory in 1949) Bjerhammar (1975), (1985) and (1986) presented pioneer studies on relativistic geodesy for height and/or geoid determination by atomic clocks. Today such clocks have become accurate enough for realizing these ideas, which fuels a hectic research interest in the topic, particularly in Germany.

\subsection{Geodynamic studies: the Fennoscandia land uplift}

In the late 1970-ties Bjerhammar completed some articles that reveal a high correlation between (a spectral window of) the gravity field and the on-going land uplift in Fennoscandia (e.g., Bjerhammar 1977 and 1980). In Bjerhammar et al. (1983) such data are used in an original geodetic method to estimate the viscosity of the upper mantle.

\subsection{Other research activities and commitments}

During 1962 and 1966 Bjerhammar worked as Director of the U.S. Army Research Institute. His achievements are reported in Sect. 7.

$\mathrm{He}$ chaired the International Association of Geodesy study group on Statistical Methods in Geodesy (1963-1967). Some of his theoretical experiences are reflected in Bjerhammar (1973, Chap. 18).

In 1977 he was appointed external expert by the Swedish government in the investigation of the accidental grounding of the Soviet oil vessel Tsesis outside the Swedish coast in the Baltic Sea. (As a bonus from this duty, KTH got its first two satellite positioning Doppler receivers, the fore-runner equipment to GPS technology.) 


\section{The focused professor}

There are many small anecdotes related with Bjerhammar that show that he is a hard thinking, dedicated professor, and here follow a few of them.

When I was a PhD student the window of my office was facing the street near the entrance to the School of Surveying. One winter day I noticed that Bjerhammar came wearing a strange fir hat, and at lunch time I saw him leaving for lunch with the same hat. After lunch he came to me and said that he did not find his hat when leaving the canteen. I told him that his hat looked a bit strange, but he did not take notice. In the afternoon he returned and reported that his wife had called him saying that she could not find her hat. So Bjerhammar had just been back to the canteen to find his wife's hat on the shelf.

Bjerhammar was very proud of telling his students that prof. Moritz was one of the few geodesists that early appreciated his method of using analytical continuation in gravimetric geoid determination (the KTH approach). He gladly described that it happened while they were out for a walk during a break at the IUGG conference in San Francisco in 1967.

In 2018 I had the pleasure to tell this story to prof. Moritz, who responded that he remembered this event very well. "We were walking along the shoreline of the San Francisco Bay and in the fund was the Golden Gate Bridge. I am totally sure that Bjerhammar saw nothing of the splendid view, as he was fully occupied by presenting his theory".

When T. Krarup started to work on his publication "foundations of physical geodesy" (Krarup 1969) his ambition was to prove that Bjerhammar's method did not work well. However, at the end he was excited, and his approach, least-squares collocation, can be regarded as another form of Bjerhammar's method. After its publication, Krarup's report was discussed at depth at KTH. Therefore, it was a great surprise to all participants that Bjerhammar did not turn up at Krarup's seminar at UU the year after publication.

At the Hotine - Marrussi symposium dinner in Turin in 1999 I had the pleasure to sit next to Krarup, and I mentioned that I participated at his Uppsala seminar."Yes”, Karup said, "I remember there were some students from KTH, but Bjerhammar did not participate. However, he called me in the night, and we decided to meet next day at Stockholm Central station on my return to Copenhagen. I expected that he wanted to get a summary of my talk, but to my surprise he was only interested in presenting his own ideas".

\section{Prizes and other Recognitions}

Bjerhammar was honored with many prizes. Here follows a list of the most important ones:

- Certificate of Achievement in 1967, U.S. Army

- The Gauss-medal in 1969, The scientific society of Braunschweig, Germany

- The North Star Order in 1971, The King of Sweden

- The Great Prize of KTH in 1982 (Fig. 1)

- Levallois medal in 1987, International Association of Geodesy

- The Rossby Prize in 1988, The Swedish Geophysical Society

- Honorary doctor at Graz University of Technology in 1988

Among the prizes, Bjerhammar was most proud of the Gauss medal, which he compared with the Nobel Prize in physics. However, for people in general, his achievement of the North Star Order should be more interesting.

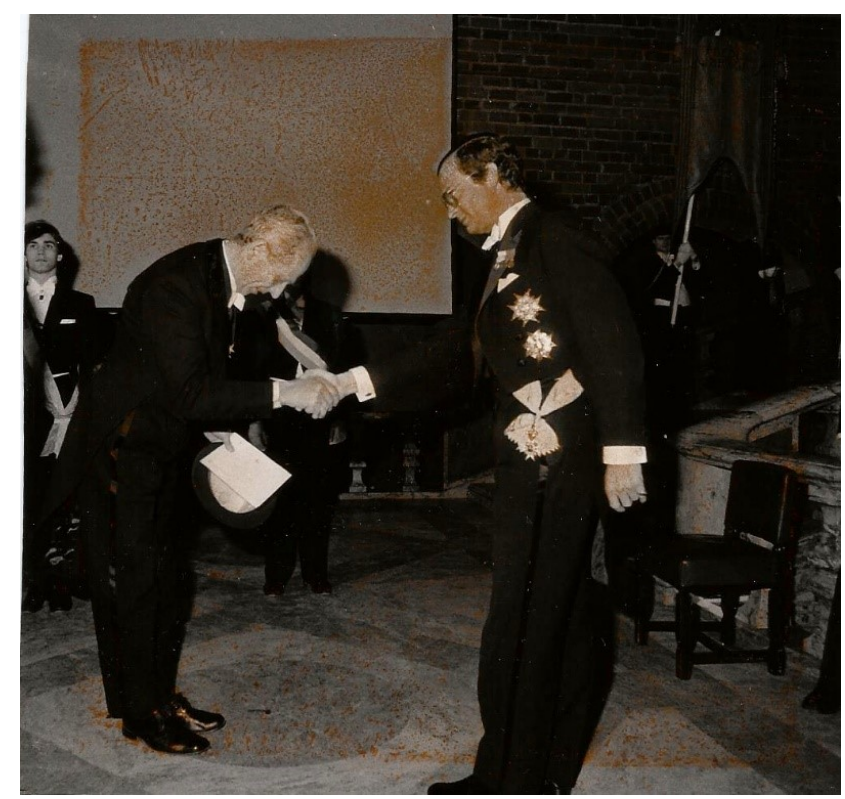

Fig. 1. Bjerhammar is awarded the KTH Great Prize in 1982.

\section{Why did Bjerhammar receive the North Star Order?}

Bjerhammar received the North Star Order in 1971, an award which at that time was intended as a reward for both 
Swedes and foreigners "for civic merits, for civil service, for sciences, weathering, learned and useful work, and for new and useful institutions". Hence, what was the specific for Bjerhammar to receive this noble award?

In January 2018, when I cleaned out old writings and binders and other things at KTH, I occasionally came across an interesting master's thesis by Nils Bruzelius (2003). Bruzelius, who was then a retired submarine captain conducting a small research project for a master's thesis in history at Stockholm University, visited me in 2003 to get information about Bjerhammar's former funded research with the USA in the early1960's. He briefed me what his work was about, and I told him the little I knew. I suggested that he should contact Bjerhammar directly in his home, which he did. After completing the thesis, Bruzelius sent me a copy, which I just glanced at and put it in my files.

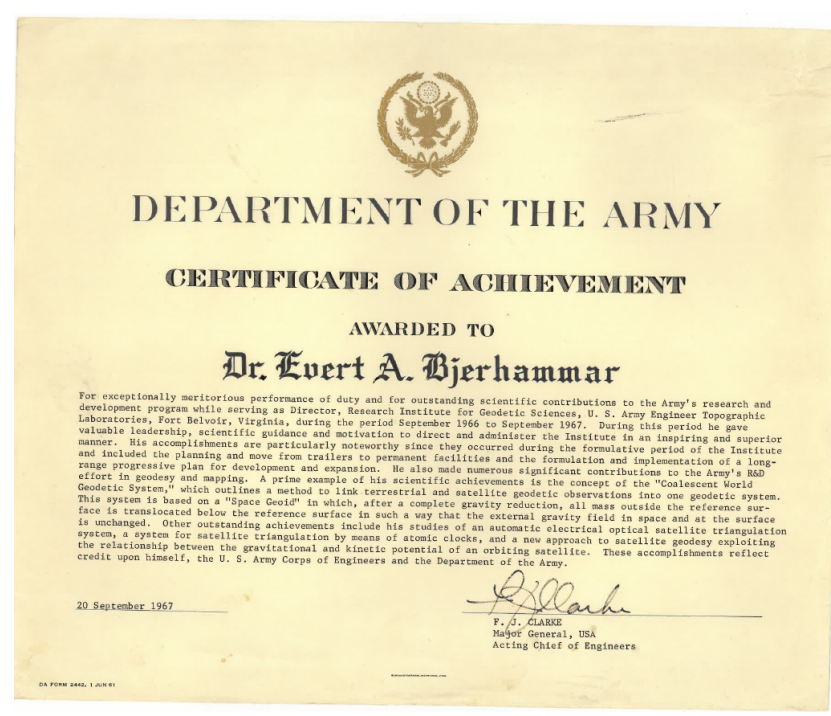

Fig. 2. The Certificate of Achievement awarded by the US Army in 1967.

The title of the master's thesis is: US defense guarantee for Sweden during the Cold War from a submarine perspective. There, Bruzelius writes that considerable research in physical geodesy at KTH was paid by the USA with the main purpose of better calculating orbits for satellites and ballistic robots. Bjerhammar also traveled to the United States in the fall of 1960, where he conducted a lecture tour at 23 colleges and universities, and during 1966 he served as Director of the US Army Research Institute. Later his American host sent a letter of thanks, with overwhelming praise, to the Swedish ambassador in the United States, who contacted KTH's Rector and the Swedish king. Bruzelius writes: "Bjerhammar stands out as an exception- ally skilled researcher" and "Bjerhammar also formulated the scientific basis for what became today's satellite-based navigation system GPS ". [The last item Bjerhammar also told me in confidence some year before his death (as "it should be a secret for 50 years").]

The overwhelming gratitudes of Bjerhammar's scientific work by the US Army was documented in September 1967 with a Certificate of Achievement signed by Major General F. J. Clarke (Fig. 2). The certificate confirms much of the facts presented above, not the least in the summary of Bjerhammar's scientific production. Hence, Bruzelius' thesis provides a reasonable explanation why Bjerhammar was honored with the North Star Order.

\section{Concluding remarks}

Scientific discussions with Arne Bjerhammar were always engaging, inspiring, intensive and inventive. No one was left unmoved. He put Swedish geodesy on the world map and was praised by several Swedish and international prizes. His US supported research in the 1960-ties not only contributed to long-term geodetic development, but, obviously, also to political relaxation during the cold war.

Arne Bjerhammar's versatile scientific ideas led to many new insights in geodetic research, some of which have not yet been explored. Most obvious is the message in his papers on relativistic geodesy, which only now are at the eve of being practically realized.

In 2017 the KTH Geodesy Division arranged a public meeting, and the same year a textbook was published by Sjöberg and Bagherbandi (2017), honoring his centennial anniversary and reviving some of his research ideas. Unfortunately, since then his memory is fainting away at KTH, where he served and won the KTH Great Prize. Although his two text - books are still available on the shelf at the Division of Geodesy, major part of his scientific production can only be found in unordered boxes in the basement of the building, and there are no more copies of his certificates and prizes to be seen along the walls. Two recent calls for new professors in Geodesy did not promote the continuation of the world-famous research in the spirit of KTH's geodetic giant Arne Bjerhammar.

\section{References}

Ågren J. et al., 2016, The NKG2015 gravimetric geoid model for the Nordic-Baltic region, Presented at the international sympo- 
sium on GGGH systems, 19-23 September 2016, Thessaloniki, Greece

Andersen O. B. (Ed.), 2001, Nordic Geodetic Commission - the first 50 years. Kort- \& Matrikelstyrelsen, Copenhagen, Denmark

Asplund L., 1945, Ueber einige methoden fuer die Ausgleichung grosser Dreiecksnetze. Mit praktischer Anwendung im Suedschwedischen Ausgleichungsgebiet der Baltischen Geodätischen Kommission, Diss. KTH (43), Stockholm

Bjerhammar A., 1948a, A contribution to the methods of optical distance measuring, specially with regard to the problems of automatic plotting, Diss. KTH (1948), Stockholm

Bjerhammar A., 1948b, Några synpunkter på matriskalkylens användning inom utjämningsräkningen. Sven. Lantmäteritidskr. 6, 460-489

Bjerhammar A., 1955, En ny matrisalgebra, Svensk Lantmäteritidskr., $5 / 6$

Bjerhammar A., 1957, A generalized matrix algebra, N.R.C. Can. Div. Appl. Phys., Ottawa

Bjerhammar A., 1962a, Geodesi (In Swedish), Almqvist and Wiksell, Stockholm

Bjerhammar A., 1962b, On an explicit solution of the gravimetric boundary value problem for an ellipsoidal surface of reference, Division of Geodesy, Royal Institute of Technology, Stockholm.

Bjerhammar A., 1963, A new theory of gravimetric geodesy Division of Geodesy, Royal Institute of Technology, Stockholm.

Bjerhammar A., 1969a, On the energy integral for satellites, Tellus, 21(1): $1-9$

Bjerhammar A., 1969b, Studies on a coalescent world geodetic system, Tellus 21(4), 517-548

Bjerhammar A., 1972, A determination of the velocity of light using the twin superheterodyne principle, Tellus 24(5), 481-495

Bjerhammar A., 1973, Theory of errors and generalized matrix inverses, Elsevier Scient. Publ. Co., Amsterdam-London-New York

Bjerhammar A., 1975, Discrete approaches to the solution of the boundary value problem in physical geodesy, Boll. Geod. e Sci. Aff. 24(2)

Bjerhammar A., 1977, The gravity field in Fennoscandia and postglacial crustal movements. Division of Geodesy, Royal Institute of technology, Stockholm, Sweden

Bjerhammar A., 1980, Postglacial uplifts and geopotentials in Fennoscandia, In N. A. Mörner (Ed.), Earth Rheology, Isostasy and Eustasy, John Wiley and Sons, 323-326

Bjerhammar A., Stocki S. and Svensson L, 1983, A geodetic determination of viscosity, Division of Geodesy, Royal Institute of Technology, Stockholm, Sweden

Bjerhammar A., 1985, On a relativistic geodesy, Bull. Geod. 59, 207 220

Bjerhammar A, 1986, Relativistic geodesy. Technical report. NOAA, National Geodetic Survery 36

Bruzelius N., 2003, USAs försvarsgaranti för Sverige under kalla kriget ur submarint perspektiv, Magisteruppsats, Historiska institutionen, Stockholms universitet (39 pages)

Freeden W. and Nashed M. Z. (Eds.), 2018, Handbook of Mathematical Geodesy, Springer Int. Publ. AG, Cham, Switzerland

Krarup T., 1969, A contribution to the mathematical foundation of physical geodesy. Geod Inst Medd No. 44, Copenhagen

Rao C. R., 1962, A note on a generalized inverse of a matrix with applications to problems of mathematical statistics, J. R. Stat. Soc., B., 24,152-158
Sjöberg L. E. 1976, Determination of refraction by an interferometer. (In Swedish), Svensk Lantmäteritidskrift 68(3),148 -153

Sjöberg L. E., 1996, In memoriam: Erik Tengström (1913 -1996), IAG Newsletter 1996.6

Sjöberg L. E., 2011, Obituary for Arne Bjerhammar, J Geodesy 85: 255-256

Sjöberg L. E. and Bagherbandi M., 2017, Gravity inversion and integration - theory and applications in Geodesy and Geophysics, Springer International Publishing AG

Tengström E., 1954, Outlines of a method for determining the geoid in Sweden by free-air anomalies, Statens Reproduktionsanstalt, Stockholm 